\title{
Synthesis of Three dimensional Mo-Doped Nickel Sulfide Mesoporous Nanostructures/Ni Foam Composite for Supercapacitor and Overall Water Splitting
}

Songyang Li, ${ }^{1}$ Jincheng Fan,,${ }^{1, *}$ Shidong Li, ${ }^{1}$ Hongguang Jin, ${ }^{1}$ Wenbin Luo, ${ }^{1}$ Yong Ma, ${ }^{2, *}$ Jianghong Wu, ${ }^{1,3}$ Zisheng Chao, ${ }^{1, *}$ Nithesh Naik, ${ }^{4}$ Duo Pan ${ }^{5,6}$ and Zhanhu Guo ${ }^{5, *}$

\begin{abstract}
Three-dimensional (3D) Mo-doped nickel sulfide $\left(\mathrm{Ni}_{3} \mathrm{~S}_{2}\right)$ mesoporous nanostructures on $\mathrm{Ni}$ foam were successfully synthesized via the solvothermal method, which showed superior properties for energy storage and conversion. As an electrode for supercapacitors, 3D Mo-doped $\mathrm{Ni}_{3} \mathrm{~S}_{2}$ mesoporous nanostructures demonstrated a $604.4 \mu \mathrm{Ah} \mathrm{cm}^{-2}$ specific capacity and good cycling stability. Furthermore, Mo-doped $\mathrm{Ni}_{3} \mathrm{~S}_{2}$ mesoporous nanostructures exhibited superior hydrogen evolution reaction and oxygen evolution reaction properties and good cycle stability for water splitting. At $1.41 \mathrm{~V}$, the electrolyzer made up of Mo-doped $\mathrm{Ni}_{3} \mathrm{~S}_{2}$ mesoporous nanostructures reached the $10 \mathrm{~mA} \mathrm{~cm} \mathrm{~cm}^{-2}$ catalytic current density, demonstrating outstanding long-term durability. Furthermore, the physical characterization results and mechanism of the 3D Mo-doped $\mathrm{Ni}_{3} \mathrm{~S}_{2}$ were investigated. Therefore, the study presents the great promise of the $3 \mathrm{D}$ Mo-doped $\mathrm{Ni}_{3} \mathrm{~S}_{2}$ mesoporous nanostructures in energy conversion and storage.
\end{abstract}

Keywords: 3D Mo-doped $\mathrm{Ni}_{3} \mathrm{~S}_{2}$ mesoporous nanostructures; Electrochemical performances; Supercapacitor; Water splitting.

Received: 14 August 2021; Accepted: 03 February 2022.

Article type: Research article.

\section{Introduction}

Sustainable energy and storage applications have received much attention because of the global energy $\operatorname{crisis}^{[1-6]}$ Supercapacitors and water splitting are necessary due to their unique advantages. ${ }^{[7-10]}$ Thereinto, the supercapacitor has many desirable performances, such as high power density and excellent stability. ${ }^{[11-17]}$ The electrochemical properties of a supercapacitor are decided through the electrode material. Accordingly, it is essential to synthesize electrode materials with excellent electrochemical performance.

With its clean efficient and renewable properties, hydrogen is considered an ideal candidate to replace fossil fuels. ${ }^{[18-25]}$

\footnotetext{
1 College of Materials Science and Engineering, Changsha

University of Science and Technology, Changsha, Hunan 410114, China.

${ }^{2}$ School of Material Science and Engineering, Shandong University of Science and Technology, Qingdao 266590, China.

3 College of Health Science and Environmental Engineering, Shenzhen Technology University, Shenzhen, Guangdong 518118, China.

4 Department of Mechanical \& Manufacturing Engineering, Manipal Institute of Technology, Manipal Academy of Higher Education, Manipal-576104, Karnataka, India.
}

Among all hydrogen $\left(\mathrm{H}_{2}\right)$ energy technologies, electrocatalytic splitting of water including oxygen evolution reaction (OER) and hydrogen evolution reaction (HER) is considered to be an effective one to prepare clean energy. ${ }^{\text {[26-32] }}$ During the process, the large-scale catalysts play a significantly important role. However, there is a challenge to prepare the electrocatalysts to have high properties as well as good consistency for OER and HER processes. ${ }^{[33-35]}$

Recently, transition metal chalcogenides have been widely investigated for supercapacitor and water splitting due to their low cost, earth abundance, and low-temperature synthesis. ${ }^{[36-}$ 38] Among all transition metal chalcogenides, $\mathrm{Ni}_{3} \mathrm{~S}_{2}$ has attracted much attention due to its high electrochemical activity. Many researchers have studied $\mathrm{Ni}_{3} \mathrm{~S}_{2}$ with various morphologies as electrode materials for supercapacitors and overall water splitting. ${ }^{[39-41]} \mathrm{Kim}$ et al. prepared the supercapacitor with $\mathrm{Ni}_{3} \mathrm{~S}_{2}$ as the electrode and a $786.5 \mathrm{C} \mathrm{g}^{-}$ ${ }^{1}$ specific capacitance at $10 \mathrm{~mA} \mathrm{~cm}^{-2} \cdot{ }^{[42]}$ Especially, the asymmetric full-cell supercapacitor demonstrated a $39.7 \mathrm{~W} \mathrm{~h}$ $\mathrm{kg}^{-1}$ energy density at $833 \mathrm{~W} \mathrm{~kg}^{-1}$ power density. Co-doped $\mathrm{Ni}_{3} \mathrm{~S}_{2}$ was prepared through the hydrothermal sulfuration route, which displayed a $1826.4 \mathrm{~F} \mathrm{~g}^{-1}$ specific capacitance at $2 \mathrm{~A} \mathrm{~g}^{-1}$ and $53.9 \%$ rate capability at $20 \mathrm{~A} \mathrm{~g}^{-1} \cdot{ }^{[43]}$ 
When $\mathrm{Ni}_{3} \mathrm{~S}_{2}$ is used to produce $\mathrm{H}_{2}, \mathrm{Ni}_{3} \mathrm{~S}_{2}$ shows good HER and OER performances. Li et al. fabricated $\mathrm{Ni}_{3} \mathrm{~S}_{2}$ bifunctional electrocatalyst by hydrothermal method, which demonstrated the effective HER and OER actives. ${ }^{[44]}$ They considered that the electrocatalytic splitting of water by $\mathrm{Ni}_{3} \mathrm{~S}_{2}$ could be improved by tailoring the crystallographic facets. In their studies, the as-prepared $\mathrm{Ni}_{3} \mathrm{~S}_{2}$ presented appealing catalytic performances (at $\mathrm{j}=10 \mathrm{~mA} \mathrm{~cm}{ }^{-2}$, HER: $\eta=189 \mathrm{mV}$, OER: $\eta$ $=296 \mathrm{mV})$. Fe-doped $\mathrm{Ni}_{3} \mathrm{~S}_{2}$ structures as electrocatalysts were investigated for overall water splitting, revealing a $1.63 \mathrm{~V}$ cell voltage at $10 \mathrm{~mA} \mathrm{~cm}^{-2} \cdot{ }^{[45]}$

Here, we reported that $3 \mathrm{D}$ Mo-doped $\mathrm{Ni}_{3} \mathrm{~S}_{2}$ mesoporous nanostructures were fabricated onto $\mathrm{Ni}$ foam (NF) by a solvothermal route. 3D Mo-doped $\mathrm{Ni}_{3} \mathrm{~S}_{2} / \mathrm{NF}$ exhibited superior electrochemical performances. The supercapacitor based on 3D Mo-doped $\mathrm{Ni}_{3} \mathrm{~S}_{2}$ mesoporous nanostructures demonstrated good areal-specific capacitance, high rate performance, as well as excellent cyclic stability. Besides, 3D Mo-doped $\mathrm{Ni}_{3} \mathrm{~S}_{2}$ mesoporous nanostructures displayed good HER and OER properties having low overpotentials and good cycle stability for water splitting. Especially, the effects of the temperature on electrochemical performances for $\mathrm{Ni}_{3} \mathrm{~S}_{2}$ mesoporous nanostructures were also investigated, systematically. Therefore, the study presents the great promise of the 3D Mo-doped $\mathrm{Ni}_{3} \mathrm{~S}_{2}$ mesoporous nanostructures in energy conversion and storage.

\section{Experiment section}

\subsection{Materials}

All chemical reagents were purchased from Sinopharm Chemical Reagent Co., Ltd, and were used directly without further processing.

\subsection{Preparation of 3D Mo-doped $\mathrm{Ni}_{3} \mathrm{~S}_{2}$ mesoporous nanostructures on $\mathrm{Ni}$ foam}

3D Mo-doped $\mathrm{Ni}_{3} \mathrm{~S}_{2}$ mesoporous nanostructures were prepared by a facile solvothermal route. A $1 \mathrm{~cm} \times 2 \mathrm{~cm} \mathrm{Ni}$ foam was cleaned to remove the nickel oxides on the surface. To synthesize $\mathrm{Ni}_{3} \mathrm{~S}_{2}$ mesoporous nanostructures, $2.2 \mathrm{~g}$ $\mathrm{Na}_{2} \mathrm{~S} \cdot 9 \mathrm{H}_{2} \mathrm{O}$ and $0.01 \mathrm{~g} \mathrm{MoS}$ were fully dispersed into $20 \mathrm{~mL}$ ethanol. Afterward, the solution and $\mathrm{Ni}$ foam were put into an autoclave, followed by keeping them at $160^{\circ} \mathrm{C}$ for $20 \mathrm{~h}$. When it was done, $\mathrm{Ni}$ foam was washed and dried. $\mathrm{Ni}$ foam was marked S-001. Similarly, another three samples were prepared

\footnotetext{
${ }^{5}$ Integrated Composites Laboratory (ICL), Department of Chemical \& Biomolecular Engineering, University of Tennessee, Knoxville, TN 37996 USA.

${ }^{6}$ Key Laboratory of Materials Processing and Mold (Zhengzhou University), Ministry of Education, National Engineering Research Center for Advanced Polymer Processing Technology, Zhengzhou University, Zhengzhou, 450001 China.

*Email: fanjincheng2009@163.com (J, Fan); courage2010@126.com (Y. Ma); chao_zs@aliyun.com (Z. Chao);
}

in the solution containing $2.2 \mathrm{~g} \mathrm{Na} 2 \mathrm{~S} \cdot 9 \mathrm{H}_{2} \mathrm{O}$ and various contents of $0.02 \mathrm{~g}, 0.03 \mathrm{~g}$, and $0.04 \mathrm{~g} \mathrm{MoS}_{2}$, which were separately marked as S-002, S-003, and S-004.

\subsection{Materials characterization}

X-ray diffractions (XRD) were obtained by a Bruker-D8 diffractometer. The surface morphology was observed by scanning electron microscopy (SEM, Hitachi S-4800) with energy-dispersive spectroscopy (EDS) and Transmission electron microscope (TEM, Tecnai G2 F20). X-ray photoelectron spectroscopy (XPS) spectra were got by a VG Escalab210 spectrometer. Electrochemical performances were measured by employing a CHI660E electrochemical workstation. The sample, $\mathrm{Hg} / \mathrm{HgO}$, and $\mathrm{Pt}$ electrodes separately served as working, reference, and counter electrodes. Cyclic voltammetry (CV) and galvanostatic charge/discharge (GCD) tests were measured in potential ranges from 0 to 0.8 and $0-0.5 \mathrm{~V}$, respectively, in a $6 \mathrm{M} \mathrm{KOH}$ electrolyte solution. Electrochemical impedance spectroscopy (EIS) was conducted over a frequency range from $0.1 \mathrm{~Hz}$ to $100 \mathrm{kHz}$. The areal capacity is obtained by using $\mathrm{C}_{\mathrm{A}}=\mathrm{I} \times$ $\Delta \mathrm{t} /(\Delta \mathrm{V} \times \mathrm{S})$, in which I (A), $\Delta \mathrm{t}(\mathrm{s}), \Delta \mathrm{V}(\mathrm{V})$, and $\mathrm{S}\left(\mathrm{cm}^{2}\right)$ are galvanostatic current, discharging time, potential window, as well as geometric surface area. For HER and OER tests, linear sweep voltammetry (LSV) was used to investigate the HER and OER actives. All the electrode potentials were obtained by $\mathrm{E}_{\mathrm{RHE}}=\mathrm{E}_{\mathrm{Hg} / \mathrm{HgO}}+0.059 \mathrm{pH}+0.14 \mathrm{~V}$. Overpotentials were got by $\eta=E_{\text {RHE }}-1.23 \mathrm{~V}$. Tafel slope was got by $\eta=b \log j+a$, in which $\mathrm{a}, \mathrm{j}$ and $\mathrm{b}$ are constant, current density as well as Tafel slope.

\section{Results and discussion}

\subsection{Characterization of Mo-doped $\mathrm{Ni}_{3} \mathrm{~S}_{2} / \mathrm{NF}$}

Figure 1 shows the crystal composition of Mo-doped $\mathrm{Ni}_{3} \mathrm{~S}_{2} / \mathrm{NF}$ In Fig. $1 \mathrm{a}$, the peaks at $21.9^{\circ}, 31.3^{\circ}, 37.8^{\circ}, 49.8^{\circ}$, and $55.4^{\circ}$ were detected, assigned to (101), (110), (003), (113) and (122) planes of $\mathrm{Ni}_{3} \mathrm{~S}_{2}$ (PDF No. 654935). All XRD patterns show the peaks at $44.6^{\circ}$, and $52.1^{\circ}$, which well matched the (111) and (200) planes of Ni. Compared to data of pure $\mathrm{Ni}_{3} \mathrm{~S}_{2}$, the peaks of Mo-doped $\mathrm{Ni}_{3} \mathrm{~S}_{2}$ were slightly shifted towards lower diffraction angles (Fig. 1b) due to the doping of Mo into the lattice of nickel sulfides. ${ }^{[46-48]}$

Figure 2, Fig. 3, and Figs. S1-3 displays the SEM images of Mo-doped $\mathrm{Ni}_{3} \mathrm{~S}_{2} / \mathrm{NF}$ prepared with various $\mathrm{MoS}_{2}$ contents in reaction solutions. It can be seen that the $3 \mathrm{D}$ Mo-doped $\mathrm{Ni}_{3} \mathrm{~S}_{2}$ network covered the surface of $\mathrm{Ni}$ foam and presented mesoporous nanostructures with different diameters. Meanwhile, electron energy spectroscopic mapping displays the overlapped distribution of $\mathrm{Ni}, \mathrm{Mo}, \mathrm{S}$, suggesting the successful doping of Mo (Fig. 4). TEM measurements were conducted to further study the microstructures (Fig. 5). By observing the Mo-doped $\mathrm{Ni}_{3} \mathrm{~S}_{2}$ ultrasonically exfoliated from $\mathrm{Ni}$ foam, the clear lattice fringes having $0.238 \mathrm{~nm} \mathrm{~d}$-spacing was observed, corresponding to (003) plane of $\mathrm{Ni}_{3} \mathrm{~S}_{2}$ and confirmed its excellent crystallinity (Fig. 5b). 

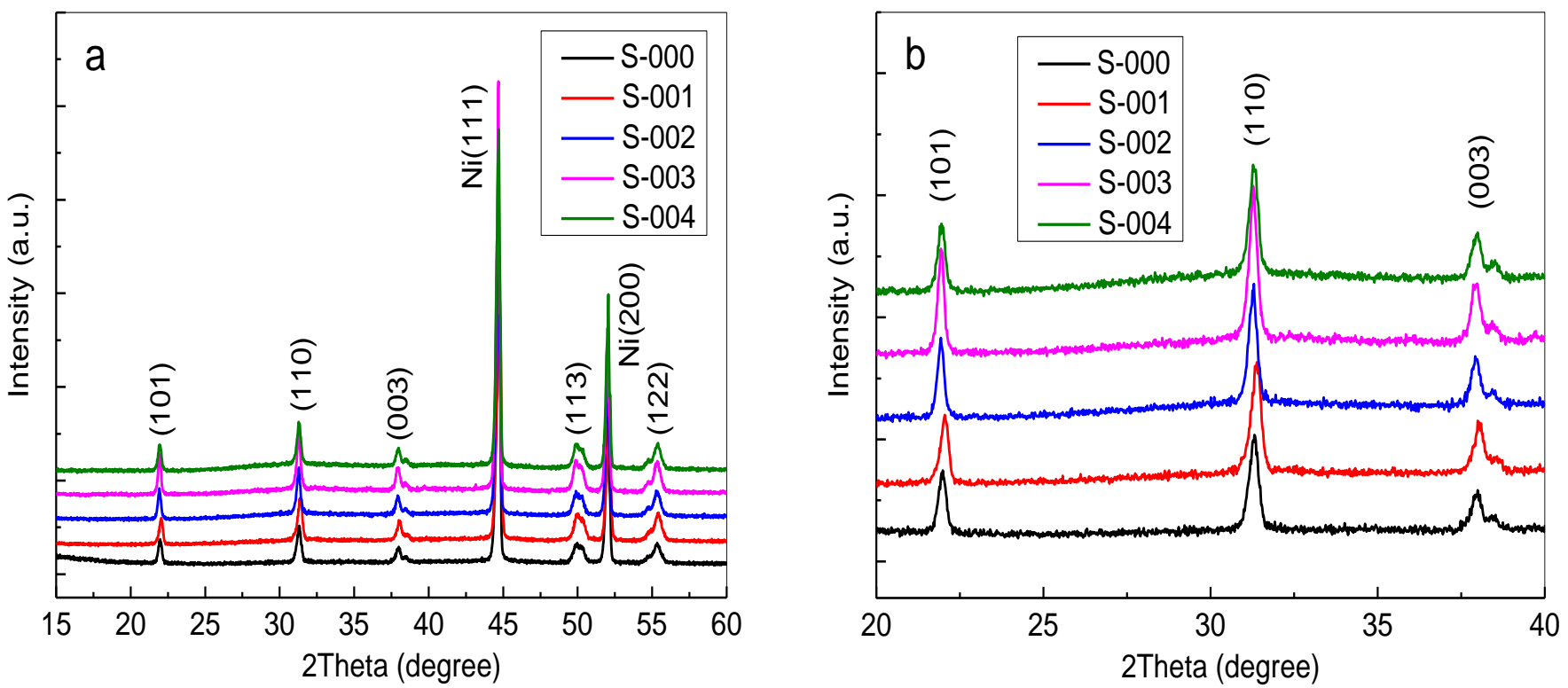

Fig. 1 (a) XRD of Mo-doped $\mathrm{Ni}_{3} \mathrm{~S}_{2}$ prepared onto the surface of $\mathrm{Ni}$ foam substrates; (b) magnified XRD in $15^{\circ}-40^{\circ}$.

XPS measurement was performed to identify the elements in Mo-doped $\mathrm{Ni}_{3} \mathrm{~S}_{2}$ mesoporous nanostructures and characterize the chemical valence states. Fig. 6a shows the typical XPS survey-scan spectrum of Mo-doped $\mathrm{Ni}_{3} \mathrm{~S}_{2}$, which presented clearly the Ni 2p, Mo 3p, Mo 3d, and S 2p peaks. As shown in Fig. $6 \mathrm{~b}$ of the Ni $2 \mathrm{p}$ spectrum, peaks at $855.5 \mathrm{eV}$ and $873.2 \mathrm{eV}$ are a result of Ni $2 \mathrm{p} 3 / 2$ and Ni $2 \mathrm{p} 1 / 2$, indicating coexisted $\mathrm{Ni}^{2+}$ and $\mathrm{Ni}^{3+}{ }^{349,50]}$ Moreover, another two peaks are viewed at $861.1 \mathrm{eV}$ and $879.2 \mathrm{eV}$ because of the shakeup-type peaks of Ni. Fig. $6 \mathrm{c}$ shows the $\mathrm{S} 2 \mathrm{p}$ spectrum, in which the peaks at $162.8 \mathrm{eV}$ and $163.5 \mathrm{eV}$ of metal-sulfur bonds. Besides, one satellite peak at $168.5 \mathrm{eV}$ is also seen, which is assigned to the $\mathrm{S}-\mathrm{Ni}$ bond. ${ }^{[47,51]}$ The Mo $3 \mathrm{~d}$ spectrum consists of three peaks at $226.90 \mathrm{eV}, 228.2 \mathrm{eV}$ as well as $232.3 \mathrm{eV}$ by fitting, respectively. The former is indexed to Mo-S, and the latter is caused by $\mathrm{Mo}^{4+} 3 \mathrm{~d} 5 / 2$ and $\mathrm{Mo}^{4+} 3 \mathrm{~d} 3 / 2 .{ }^{[52]}$
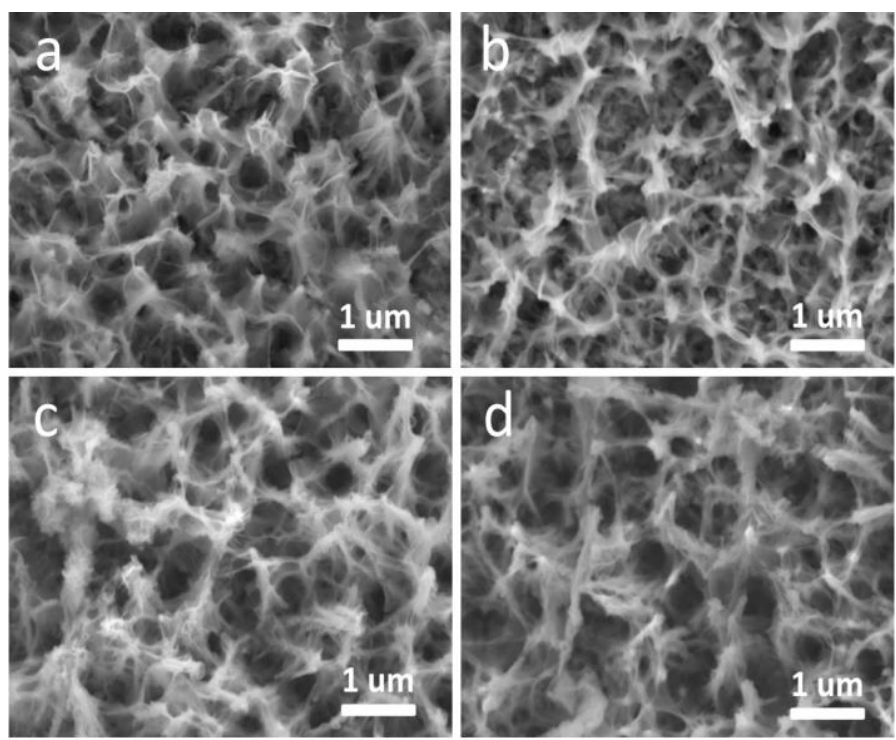

Fig. 2 SEM images of S-001(a), S-002(b), S-003(c) and S-004(d).
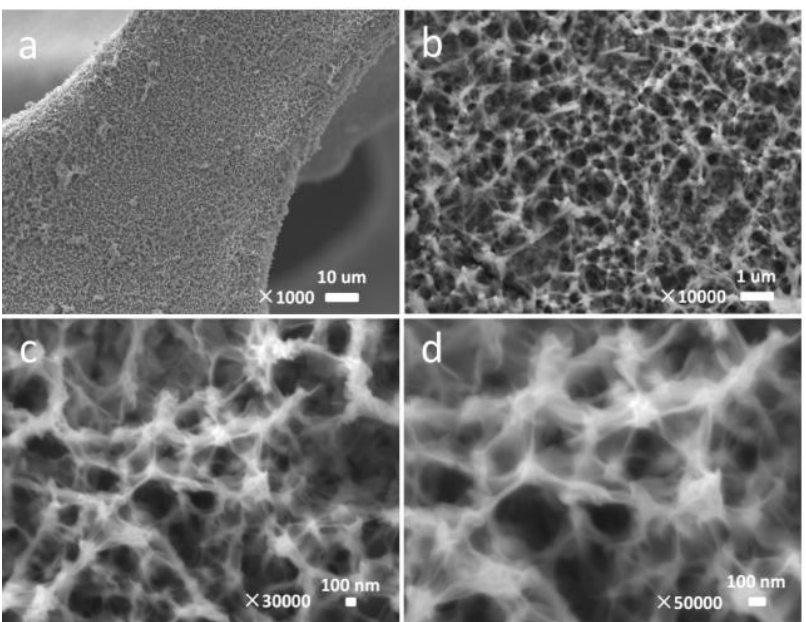

Fig. 3 SEM images of S-003 with different magnifications:(a) $\times 1000$; (b) $\times 10000$; (c) $\times 30000$; (d) $\times 50000$.
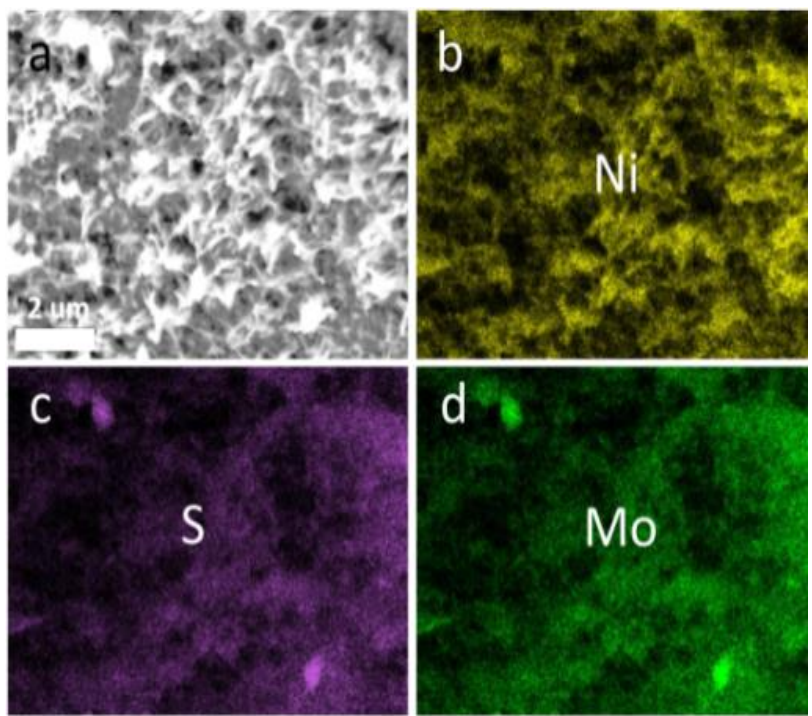

Fig. 4 The typical EDS mapping images of Mo-doped $\mathrm{Ni}_{3} \mathrm{~S}_{2}$ mesoporous nanostructures (S-002). 

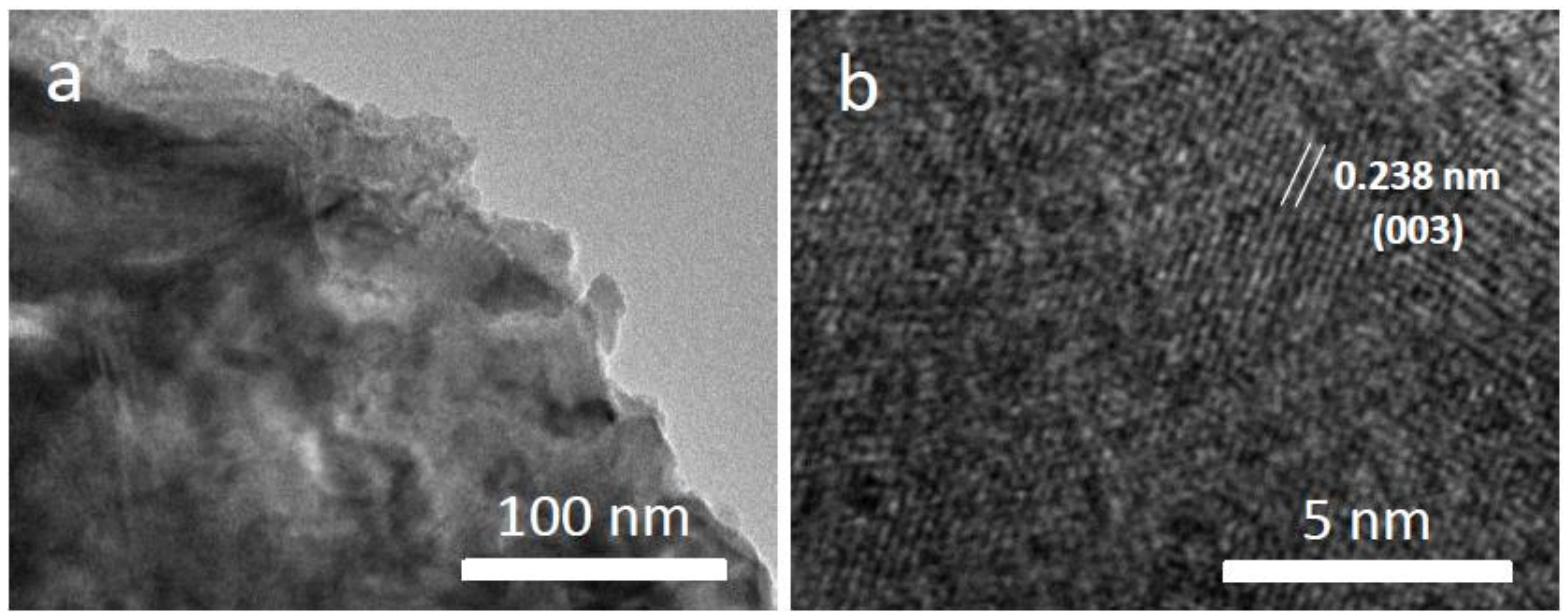

Fig. 5 The TEM (a) and HRTEM (b) images of Mo-doped $\mathrm{Ni}_{3} \mathrm{~S}_{2}$ nanostructures (S-003).
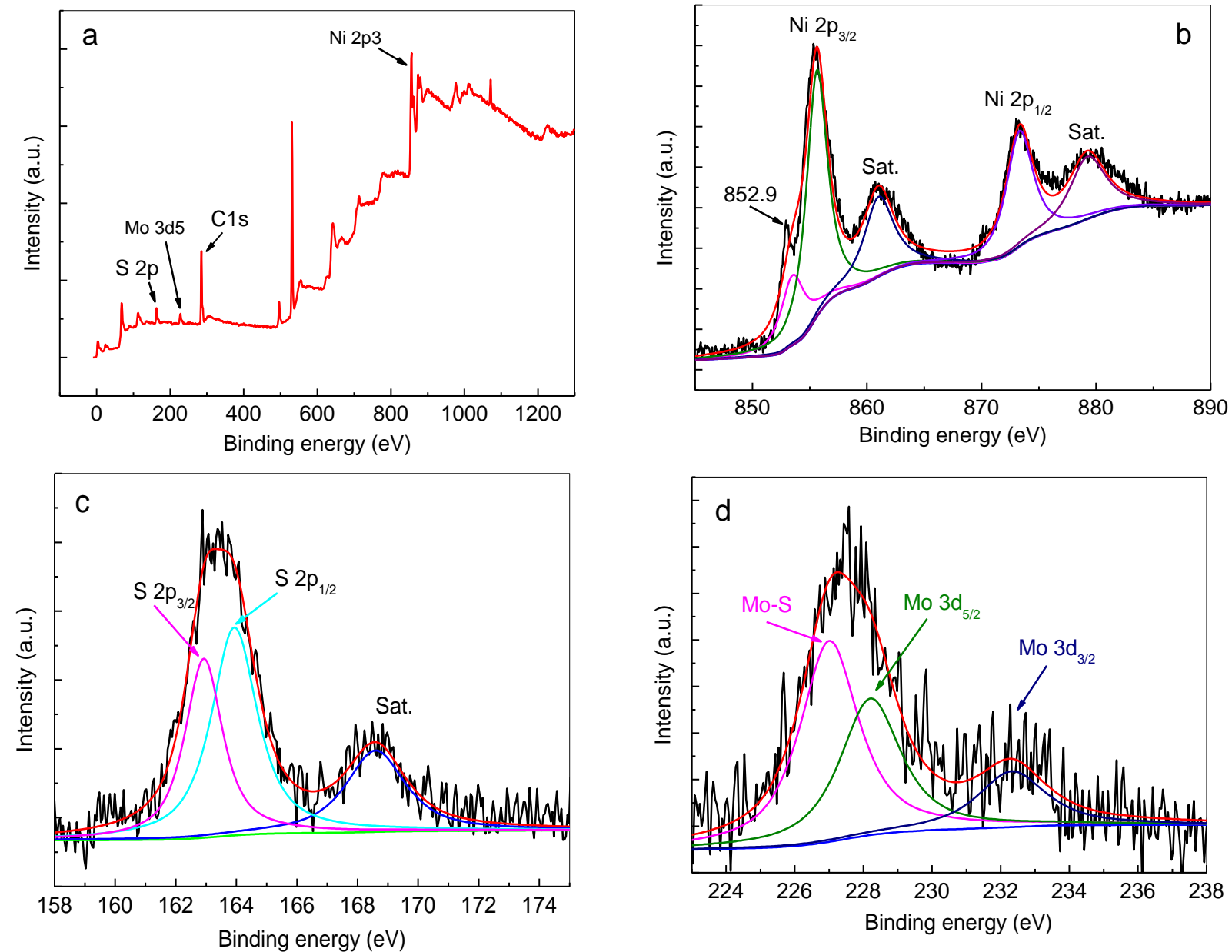

Fig. 6 The typical XPS spectra of Mo-doped $\mathrm{Ni}_{3} \mathrm{~S}_{2}$ mesoporous nanostructures (S-003): (a) the full spectrum; (b) Ni (c) S and (d) elements.

3.2 Electrochemical performances of Mo-doped $\mathrm{Ni}_{3} \mathrm{~S}_{2}$ mesoporous nanostructures/NF

was performed at $2.5 \mathrm{~mA} \mathrm{~cm}{ }^{-2}$ within $0-0.5 \mathrm{~V}$. The charging/discharging profiles were observed for all samples, The electrochemical performances of the samples were indicating the pseudocapacitive character of Mo-doped $\mathrm{Ni}_{3} \mathrm{~S}_{2}$ evaluated (Fig. 7). Fig. 7a shows the CV curves of Mo-doped mesoporous nanostructures. The discharging duration for S$\mathrm{Ni}_{3} \mathrm{~S}_{2}$ mesoporous nanostructures grown with different $\mathrm{MoS}_{2} \quad$ 001, S-002, S-003, and S-004 were $231.7 \mathrm{~s}, 240.6 \mathrm{~s}, 398.2$ contents. All electrodes exhibited redox peaks in $-0.2 \mathrm{~V}-0.8 \mathrm{~V}, \mathrm{~s}$, and $281.1 \mathrm{~s}$, and the calculated areal capacities were 321.8, in accordance with the redox reaction: $334.2,553.1 \mu \mathrm{Ah} \mathrm{cm}^{-2}$ as well as $390.4 \mu \mathrm{Ah} \mathrm{cm}^{-2}$, respectively. $\mathrm{Ni} / \mathrm{Co}-\mathrm{S} \leftrightarrow \mathrm{Ni} / \mathrm{Co}-\mathrm{S}-\mathrm{OH} .{ }^{[43,53]}$ In Fig. 7b, GCD of the samples To further investigate the conductivity of Mo-doped $\mathrm{Ni}_{3} \mathrm{~S}_{2}$ 
mesoporous nanostructure, EIS measurements were carried out on the samples. Fig. 7c demonstrates the corresponding Nyquist plots. All the samples exhibit small equivalent series resistance (Rs). In the high-frequency region, the S-003 electrode had lower Rs of $0.495 \Omega$, compared to S-001 (Rs: $0.643 \Omega$ ), S-002 (Rs: $1.919 \Omega$ ), and S-004 (Rs: $4.685 \Omega$ ). The result indicated $\mathrm{S}-003$ has better electrical conductivity and kinetics of charge transfer. Besides, a semicircle of S-004 was found, revealing a large charge transfer resistance $\left(\mathrm{R}_{\mathrm{ct}}\right)$. In the low-frequency region, S-002 and S-003 displayed straight lines with similar slopes, which were larger than those of S001 and S-004, suggesting their inferior Warburg resistances (Rw), meaning bad ion diffusion.

Fig. 7d presents the CV curves of S-003 in the range of 10 $\mathrm{mV} \mathrm{s}^{-1}$ to $50 \mathrm{mV} \mathrm{s}^{-1}$. One can find that the reduction peaks and oxidation peaks shifted to positive and negative potentials
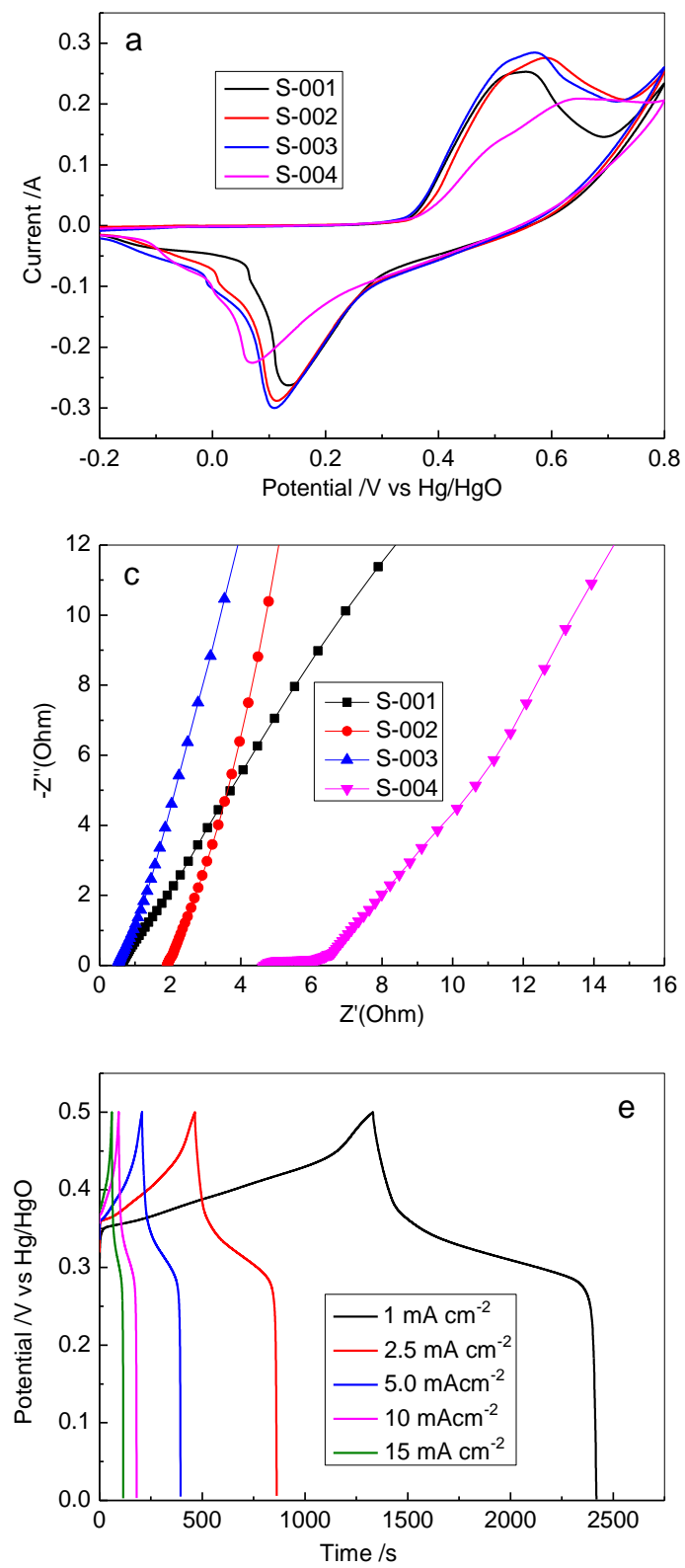
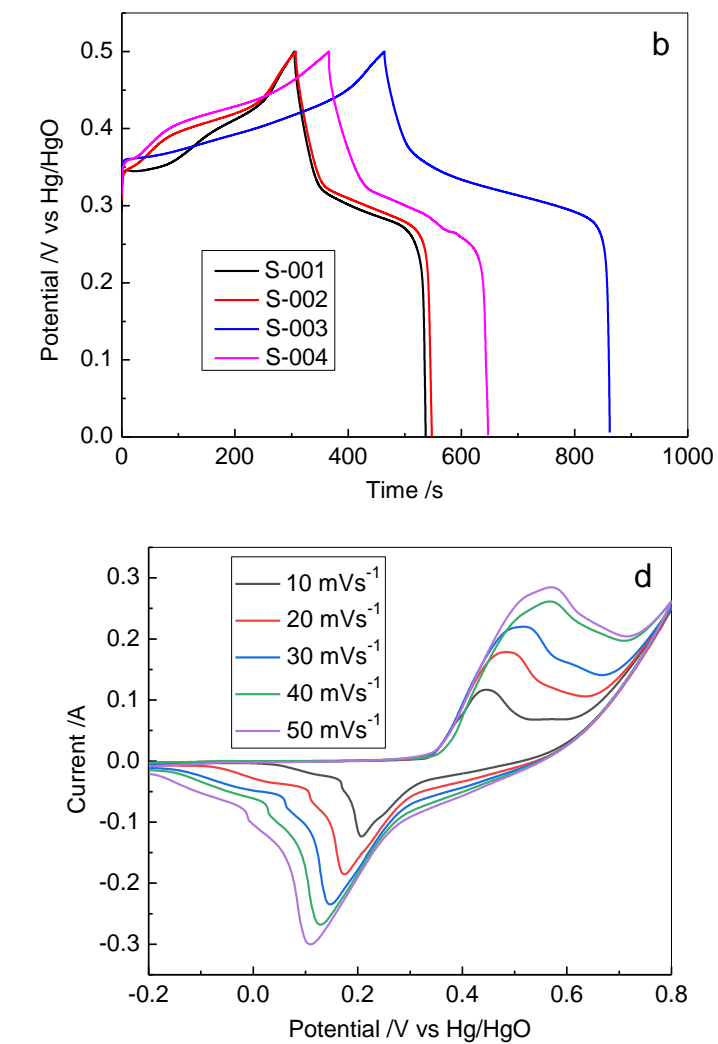

when the scan rate is increased, respectively, remaining in the symmetrical position. The result illustrated the Mo-doped $\mathrm{Ni}_{3} \mathrm{~S}_{2}$ mesoporous nanostructures could experience high current charge/discharge cycles with the reversible redox reaction. The GCD of S-003 was measured, as shown in Fig. 7e. Obviously, well-defined voltage plateaus were detected, suggesting that redox reactions occurred. Besides, the measured curves with symmetric shapes indicated an excellent coulombic efficiency in reversible redox. In the range, the areal capacity value of S-003 gradually became from 604.4 $\mu \mathrm{Ah} \mathrm{cm}^{-2}$ to $467.5 \mu \mathrm{Ah} \mathrm{cm}^{-2}$ (Fig. 7f). The capacitive performances of S-001, S-002, and S-004 were also investigated systematically, as shown in Figs. S4-6 and they demonstrated a similar situation to S-003. For S-002, the area capacity became from 393.0 to $274.2 \mu \mathrm{A} \mathrm{h} \mathrm{cm}^{-2}$ (Fig. S5c).

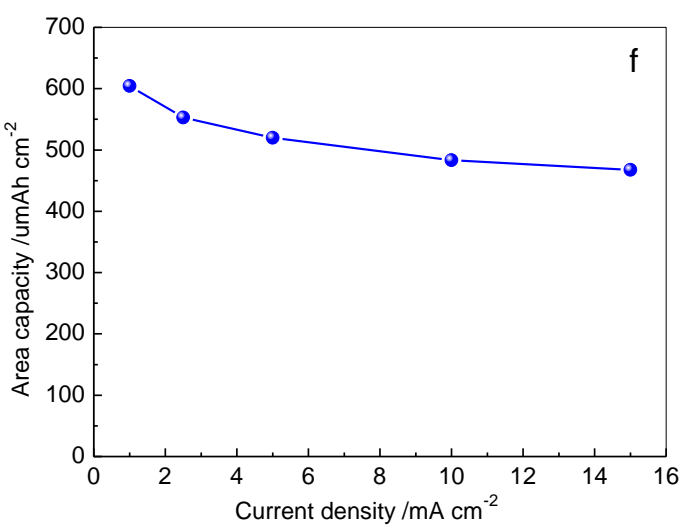

Fig. 7 (a) CV curves at $50 \mathrm{mV} \mathrm{s}^{-1}$, (b) GCD curves at $2.5 \mathrm{~mA} \mathrm{~cm}^{-2}$, (c) Nyquist curves of S-001, S-002, S-003, and S-004; (d) CV curve and (e) GCD curves and areal capacity of S-003. 

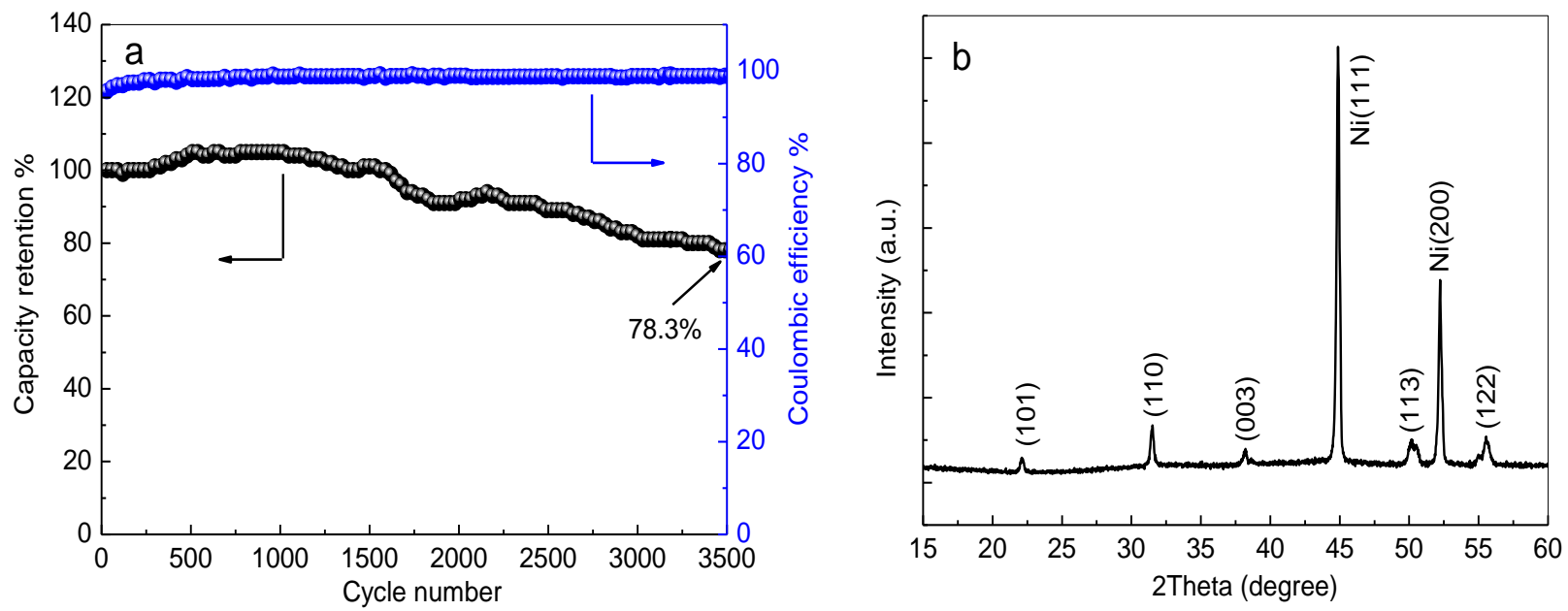

Fig. 8 (a) Cycle tests of $\mathrm{Ni}_{3} \mathrm{~S}_{2} / \mathrm{Ni}$ electrode, (b) XRD patterns of S-003 after 3500 cycles.

The cycle measurement proceeded to investigate the stable ability of Mo-doped $\mathrm{Ni}_{3} \mathrm{~S}_{2}$ mesoporous nanostructures (S-003). The electrode remained $78.3 \%$ capacitance retention after 3500 cycles, which demonstrated the excellent cycle stability of Mo-doped $\mathrm{Ni}_{3} \mathrm{~S}_{2}$ mesoporous nanostructures (Fig. 8a). Concurrently, the XRD pattern of S-003 under this test exhibited good crystallinity of Mo-doped $\mathrm{Ni}_{3} \mathrm{~S}_{2}$ mesoporous nanostructures (Fig. 8b).

The effects of measurement temperatures on electrochemical performances were investigated, as shown in

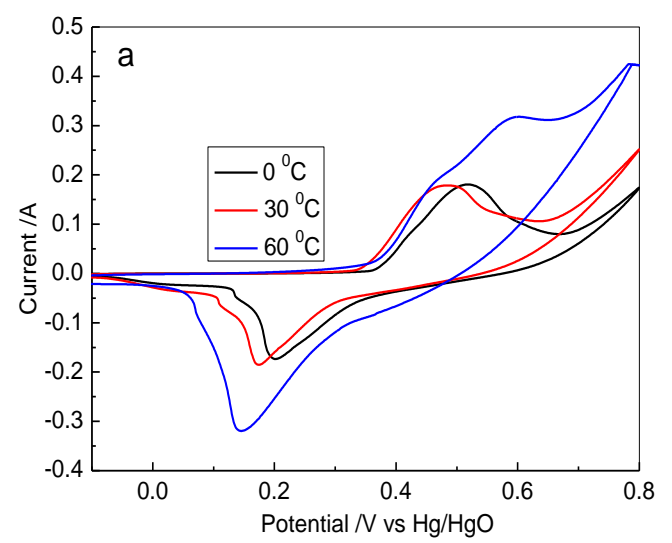

Fig. 9. Obviously, the areas of $\mathrm{CV}$ curves at higher measurement temperatures were larger than those of $\mathrm{CV}$ curves at lower measurement temperatures, suggesting the higher specific capacitance. Fig. 9b shows the Nyquist plots for $\mathrm{S}-003$ at $0-60{ }^{\circ} \mathrm{C}$, which revealed that charge-transfer resistance decreased from $0.528 \Omega\left(0^{\circ} \mathrm{C}\right)$ to $0.408 \Omega\left(60^{\circ} \mathrm{C}\right)$. As the measurement temperature soared to $60{ }^{\circ} \mathrm{C}$, the areal capacity values increased from $383.5 \mu \mathrm{Ah} \mathrm{cm}^{-2}$ to $779.2 \mu \mathrm{Ah}$ $\mathrm{cm}^{-2}$, which were in agreement with the CV and EIS results.
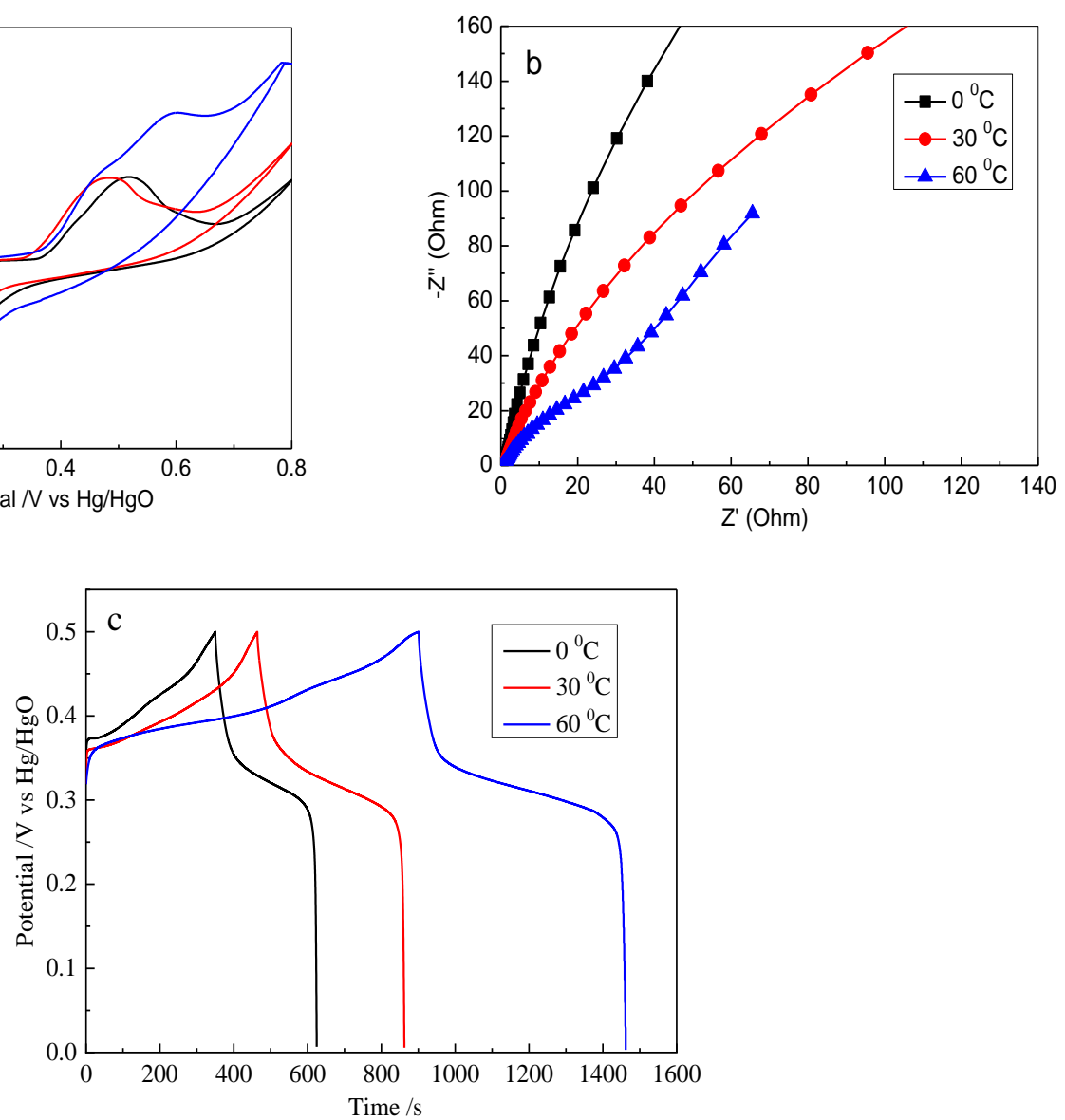

Fig. 9 The typical CV curves (a), Nyquist plots (b) and GCD profiles (c) for Mo doped $\mathrm{Ni}_{3} \mathrm{~S}_{2} / \mathrm{NF}$ electrodes (S-003). 

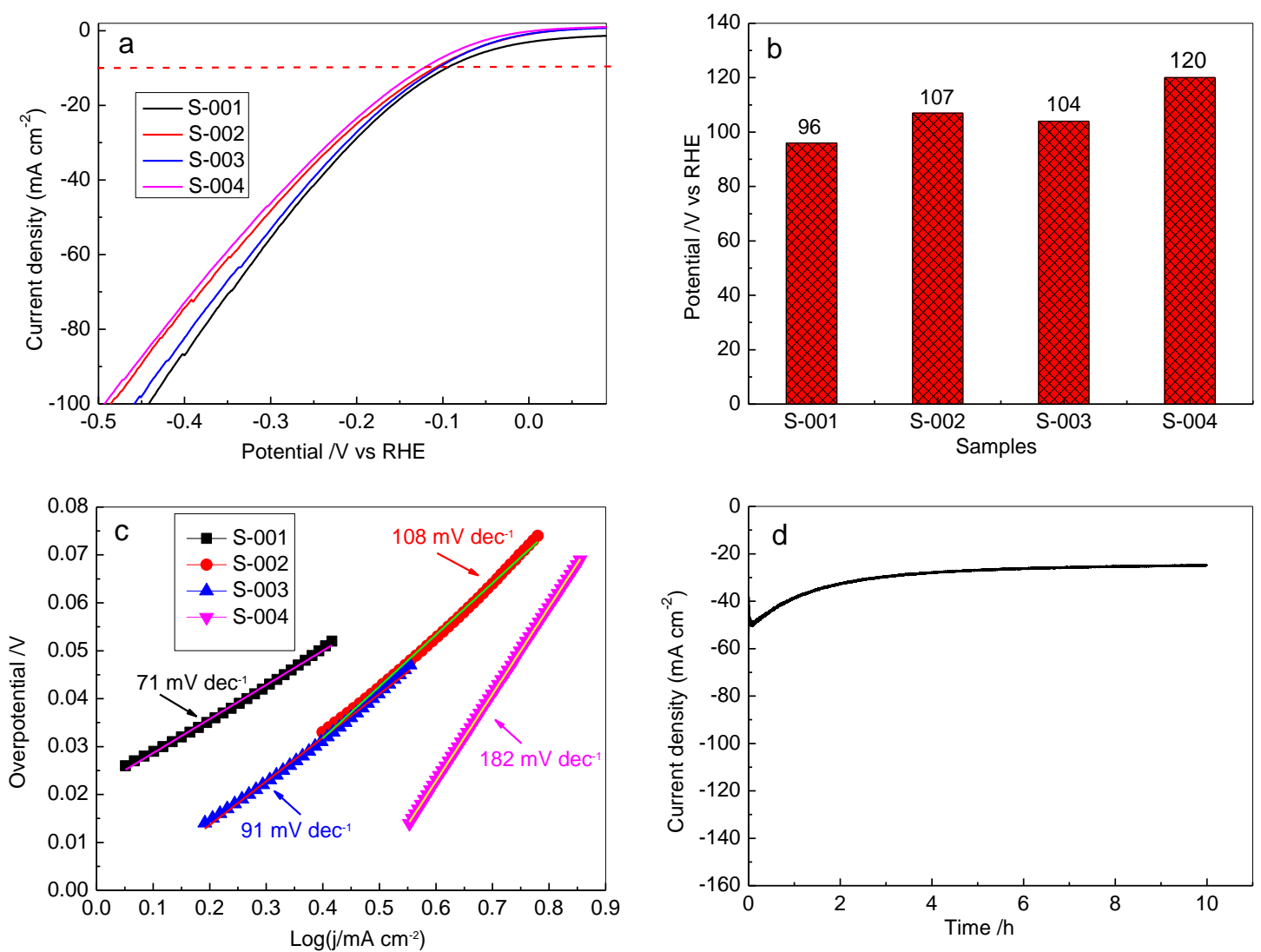

Fig. 10 (a) LSV HER of Mo doped $\mathrm{Ni}_{3} \mathrm{~S}_{2} / \mathrm{NF}$ electrodes; (b) HER overpotential values at $10 \mathrm{~mA} \mathrm{~cm}^{-2}$; (c) Tafel curves of HER.

The 3D interconnected Mo-doped $\mathrm{Ni}_{3} \mathrm{~S}_{2}$ mesoporous $\mathrm{mA} \mathrm{cm}{ }^{-2}$, The overpotentials for $\mathrm{S}-001, \mathrm{~S}-002, \mathrm{~S}-003$, and $\mathrm{S}-$ nanostructures/NF were also investigated at $5 \mathrm{mV} \mathrm{s}^{-1}$ to make 004 are $96 \mathrm{mV}, 107 \mathrm{mV}, 104 \mathrm{mV}$ and $120 \mathrm{mV}$ (Fig. 10b), lower water splitting. The LSV curves were listed in Fig. 10. At 10 than those of $\mathrm{NiCoP}(150 \mathrm{mV})^{[54]}$ and $\mathrm{Ni}_{2} \mathrm{P}$ nanotubes $(150$
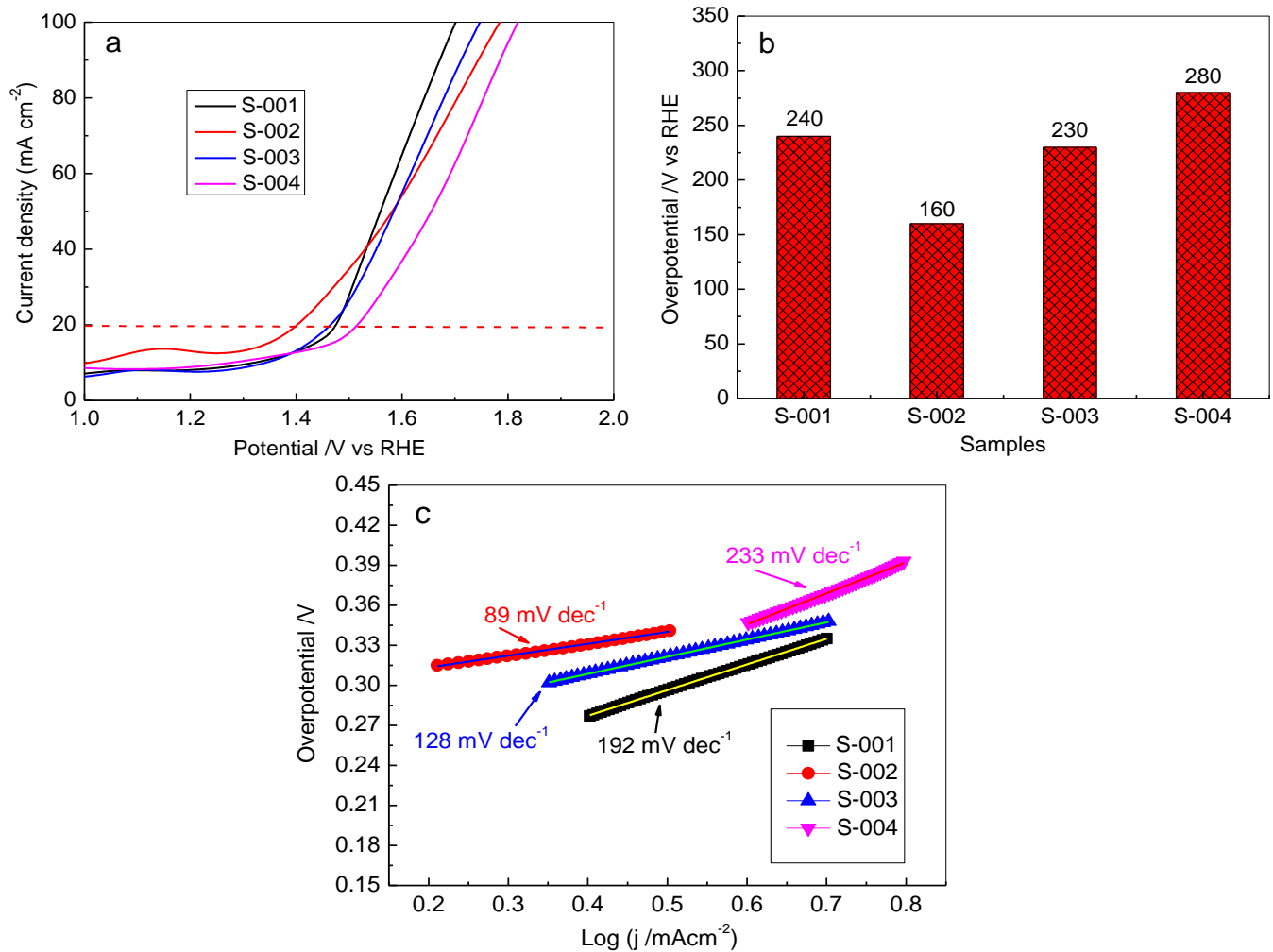

Fig. 11 (a) LSV OER for Mo-doped $\mathrm{Ni}_{3} \mathrm{~S}_{2} / \mathrm{NF}$ electrodes; (b) OER overpotential values at $20 \mathrm{~mA} \mathrm{~cm}^{-2}$; (c) Tafel curves of OER. 
$\mathrm{mV}) .{ }^{[55]}$ The Tafel slopes of S-001, S-002, S-003, and S-004 were $71 \mathrm{mVdec}^{-1}, 91 \mathrm{mVdec}^{-1}, 104 \mathrm{mVdec}^{-1}$, and $181 \mathrm{mVdec}^{-}$ ${ }^{1}$, respectively, suggesting favorable HER kinetics (Fig. 10c). Furthermore, the durability of Mo-doped $\mathrm{Ni}_{3} \mathrm{~S}_{2}$ mesoporous nanostructures/NF was investigated by i-t measurement. Fig. $10 \mathrm{~d}$ presents the typical $\mathrm{i}-\mathrm{t}$ curve of Mo-doped $\mathrm{Ni}_{3} \mathrm{~S}_{2}$ mesoporous nanostructures/NF, which delivered $10 \mathrm{~mA} \mathrm{~cm}^{-2}$
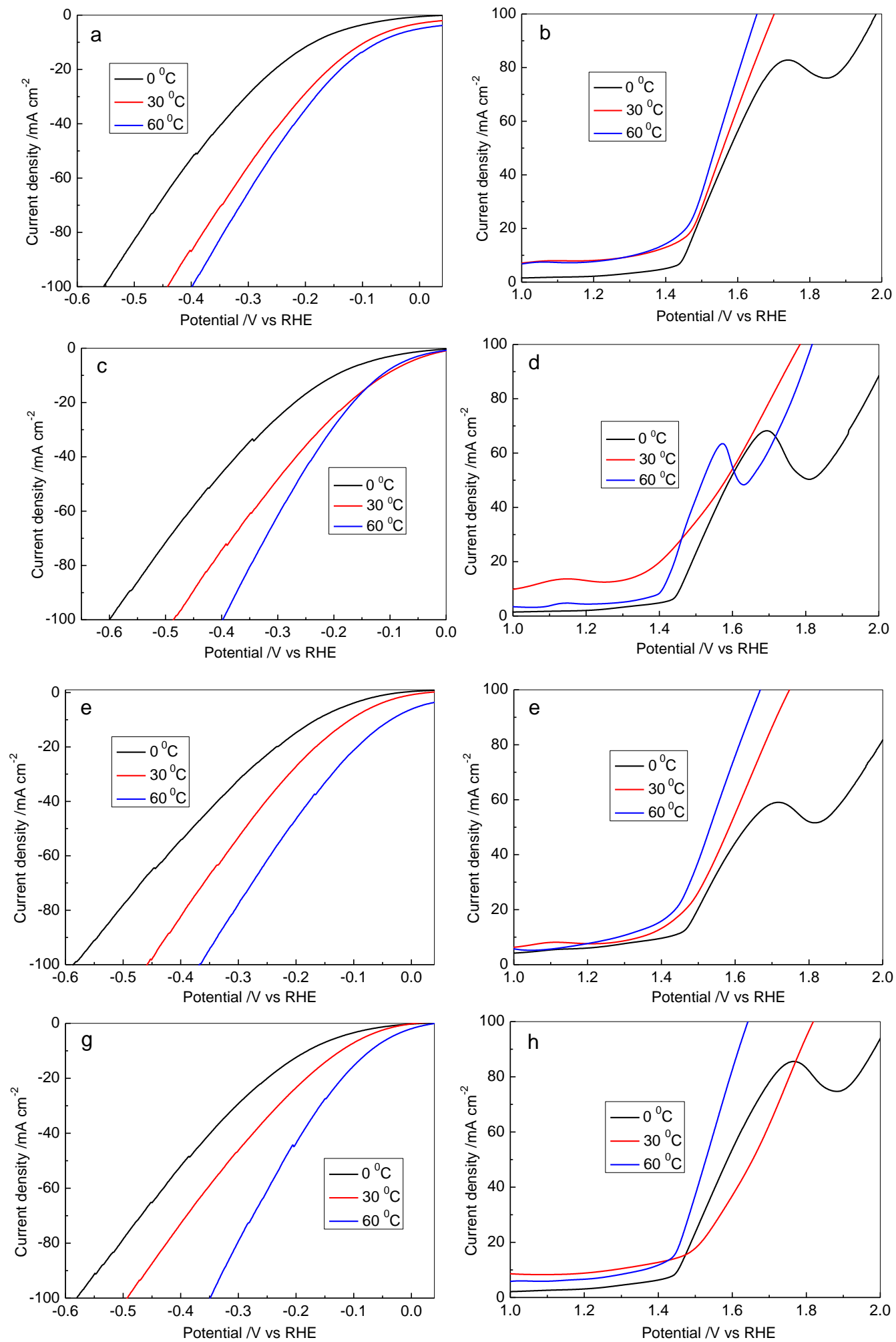

after $10 \mathrm{~h}$ and demonstrated the stable HER catalytic properties. Remarkably, the almost unchanged LSV curves further verified the super satisfactory durability (Fig. 10d: inset).

In addition, Mo-doped $\mathrm{Ni}_{3} \mathrm{~S}_{2}$ mesoporous nanostructures/NF delivered good OER properties. Fig. 11a displayed the LSV curves of S-001, S-002, S-003 and S-004
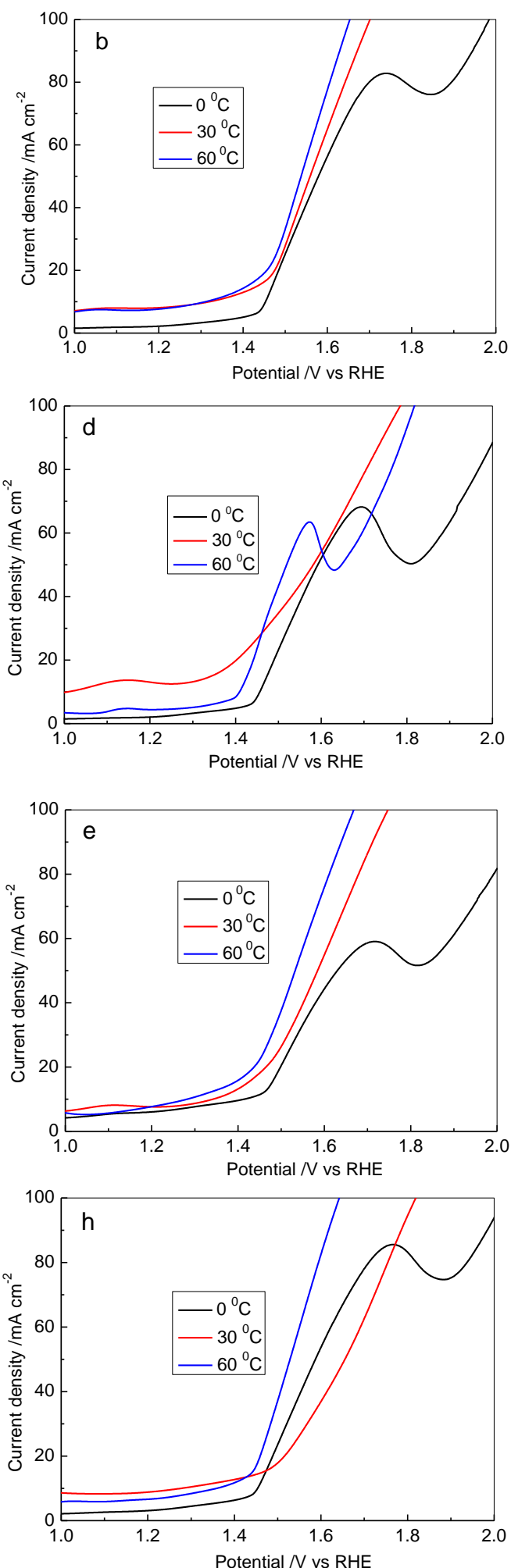

Fig. 12 LSV curves for Mo doped $\mathrm{Ni}_{3} \mathrm{~S}_{2} / \mathrm{NF}$ electrodes at various measurement temperatures: HER and OER curves at 0-60 ${ }^{\circ} \mathrm{C}$ : (a) (b) S-001; (c) (d) S-002; (e) (f) S-003; (g) (f) OER S-004. 

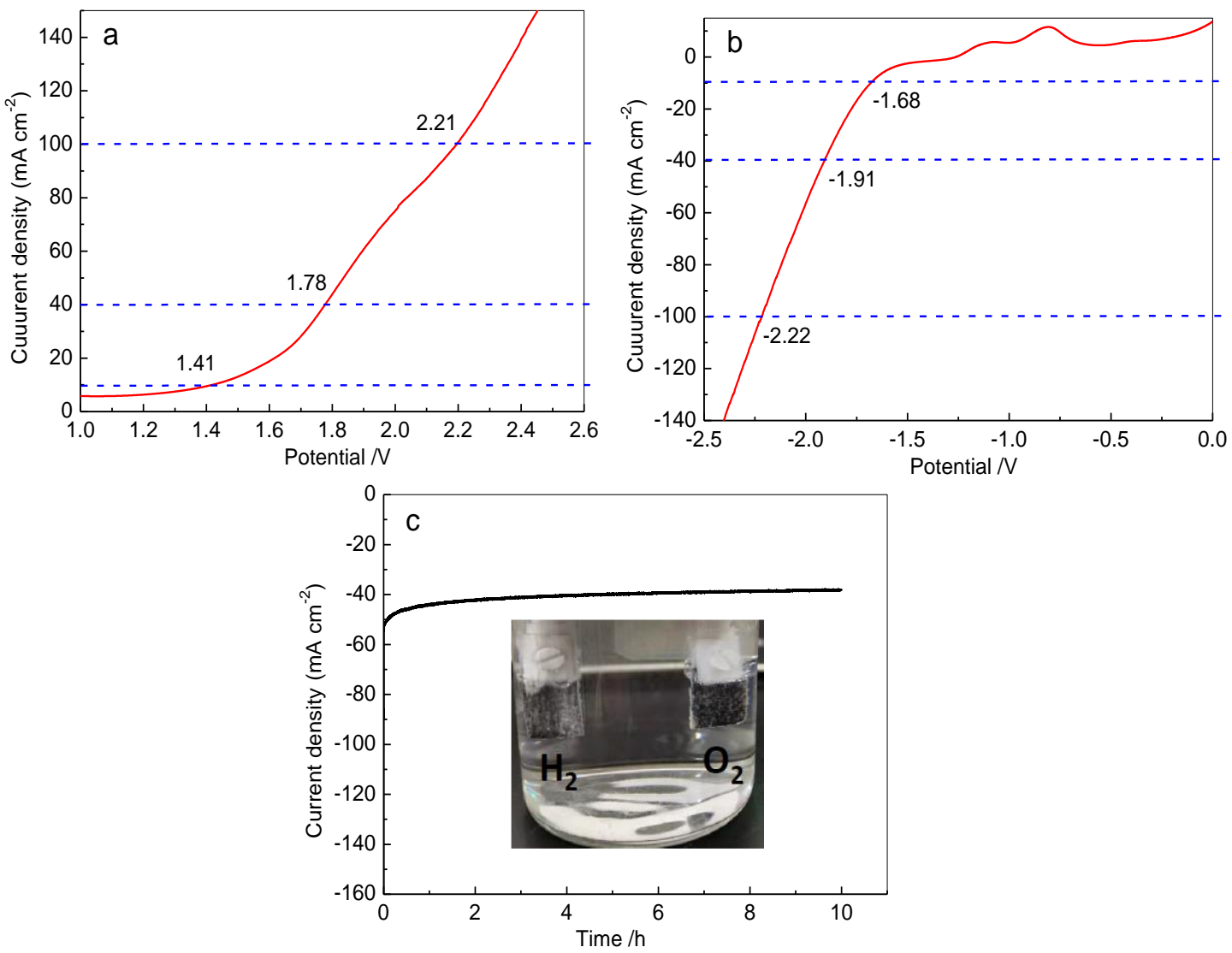

Fig. 13 Water-splitting polarization of S-001 for (a) anode and (b) cathode, (c) durability of water splitting for S-001, inset of (c) demonstrating the gas evolution.

electrodes. The S-002 electrode demonstrated the super OER activities with the lower overpotential of $160 \mathrm{mV}$ at $20 \mathrm{~mA}$ $\mathrm{cm}^{-2}$, in comparison with S-001 $(240 \mathrm{mV}), \mathrm{S}-003(230 \mathrm{mV})$ and S-004 (280 mV) (Fig. 11b). Tafel plots were employed to research the OER kinetics, as shown in Fig. 10c. The Tafel slopes for the electrode were calculated to be $192 \mathrm{mVdec}^{-1}$ for $\mathrm{S}-001,128 \mathrm{mVdec}^{-1}$ for S-002, $89 \mathrm{mVdec}^{-1} \mathrm{~S}-003$ for and 233 $\mathrm{mVdec}^{-1}$ for S-004, respectively, revealing the favorable OER reaction kinetics (Fig. 11c).

The electrocatalytic properties of Mo-doped $\mathrm{Ni}_{3} \mathrm{~S}_{2}$ mesoporous nanostructures/NF at different temperatures were further estimated. Fig. 12 shows the HER and OER behaviors of S-001, S-002, S-003, and S-004 at various temperatures. HER and OER activities for the samples presented similar changes with increasing temperature: HER and OER curves shift to the higher and lower potential, respectively. These results contributed to the external energy-enhancing HER and OER reactions. At $20 \mathrm{~mA} \mathrm{~cm}{ }^{-2}$, HER overpotentials changed from 254 to $138 \mathrm{mV}$ for S-001, 269 to $166 \mathrm{mV}$ for S-002, 238 to $97 \mathrm{mV}$ for S-003, and 247 to $117 \mathrm{mV}$ for S-004, respectively. At $40 \mathrm{~mA} \mathrm{~cm}^{-2}$, OER overpotentials changed from 256 to 225 $\mathrm{mV}$ for S- 001,326 to $261 \mathrm{mV}$ for S-002, 351 to $271 \mathrm{mV}$ for $\mathrm{S}-003$, and 247 to $117 \mathrm{mV}$ for S-004. This result shows the measurement temperature should be increased properly to enhance HER and OER activities. Based on the above experimental results, the Mo-doped $\mathrm{Ni}_{3} \mathrm{~S}_{2}$ mesoporous
nanostructures/NF hold excellent performances of HER and OER. Consequently, an electrolyzer was assembled with Modoped $\mathrm{Ni}_{3} \mathrm{~S}_{2}$ mesoporous nanostructures/NF (S-001) for water splitting. As shown in Fig. 13a, the required voltage for S-001 of $10 \mathrm{~mA} \mathrm{~cm}^{-2}$ was $1.41 \mathrm{~V}$ for the anode $-1.68 \mathrm{~V}$ and for the cathode. Moreover, the electrolyzer demonstrated a $40 \mathrm{~mA} \mathrm{~cm}^{-}$ 2 at $-1.78 \mathrm{~V}$ for $10 \mathrm{~h}$, suggesting its outstanding long-term durability. Remarkably, $\mathrm{O}_{2}$ and $\mathrm{H}_{2}$ bubbles were seen at the periphery of the electrode by unaided eyes when the electrolyzer was working (Fig. 13c inset).

\section{Conclusions}

Here, 3D Mo-doped $\mathrm{Ni}_{3} \mathrm{~S}_{2}$ mesoporous nanostructures were synthesized on the periphery of Ni foam via a solvothermal approach. Their structure and electrochemical performances were investigated, systematically. Mo-doped $\mathrm{Ni}_{3} \mathrm{~S}_{2}$ mesoporous nanostructures demonstrated excellent electrochemical performances for energy storage and conversion. As electrode materials, Mo-doped $\mathrm{Ni}_{3} \mathrm{~S}_{2}$ mesoporous nanostructures delivered an exceptional 604.4 $\mu \mathrm{Ah} \mathrm{cm}^{-2}$ specific capacitance as well as a very promising cyclic stability. Besides, 3D Mo-doped $\mathrm{Ni}_{3} \mathrm{~S}_{2}$ mesoporous nanostructures also demonstrated superior HER and OER properties with low overpotentials and good stability, indicating the potential application in water splitting. Therefore, the study presents the great promise of the 3D Mo- 
doped $\mathrm{Ni}_{3} \mathrm{~S}_{2}$ mesoporous nanostructures in energy conversion and storage.

\section{Acknowledgments}

Financial support is acknowledged by the program from the National Natural Science Foundation of China (Grant No. 51701022), the Natural Science Foundation of Hu'nan Province (Grant No. 2018JJ3528), Foundation of Hu'nan Educational Committee (Grant No. 18A149), Research and innovation projects for Postgraduates of Hu'nan Province (CX20200903), the International Collaboration Program, CSUST (No. 2018IC28) and the Creative Program from College of Materials Science and Engineering, CSUST.

\section{Conflict of Interest}

There is no conflict of interest.

\section{Supporting Information}

Applicable.

\section{References}

[1] J. M. Serra, J. F. Borrás-Morell, B. García-Baños, M. Balaguer, P. Plaza-González, J. Santos-Blasco, D. Catalán-Martínez, L. Navarrete, J. M. Catalá-Civera, Nature Energy, 2020, 5, 910-919, doi: 10.1038/s41560-020-00720-6.

[2] S. Fleischmann, J. B. Mitchell, R. Wang, C. Zhan, D. E. Jiang, V. Presser, V. Augustyn, Chemical Reviews, 2020, 120, 67386782, doi: 10.1021/acs.chemrev.0c00170.

[3] Y. Ma, Z. Zhuang, M. Ma, Y. Yang, W. Li, J. lin, M. Dong, S. Wu, T. Ding, Z. Guo, Polymer, 2019, 182, 121808, doi: 10.1016/j.polymer.2019.121808

[4] Y. Wang, Y. Liu, C. Wang, H. Liu, J. Zhang, J. Lin, J. Fan, T. Ding, J. E. Ryu, Z. J. E. S. Guo, Engineered Science, 2020, 9, 5059, doi: 10.30919/es8d903.

[5] J. Cai, W. Xu, Y. Liu, Z. Zhu, G. Liu, W. Ding, G. Wang, H. Wang, Y. J. E. S. Luo, Engineered Science, 2019, 5, 21-29, doi: $10.30919 /$ es8d669.

[6] L. Xiao, H. Qi, K. Qu, C. Shi, Y. Cheng, Z. Sun, B. Yuan, Z. Huang, D. Pan, Z. Guo, Advanced Composites and Hybrid Materials, 2021, 4, 306-316, doi: 10.1007/s42114-021-00223-2. [7] P. Simon, Y. Gogotsi, Nature Materials, 2020, 19, 1151-1163, doi: 10.1038/s41563-020-0747-z.

[8] M. Yi, B. Lu, X. Zhang, Y. Tan, Z. Zhu, Z. Pan, J. Zhang, Applied Catalysis B: Environmental, 2021, 283, 119635, doi: 10.1016/j.apcatb.2020.119635.

[9] Z. Li, Z. Lv, X. Liu, G. Wang, Y. Lin, G. Xie, L. Jiang, Renewable Energy, 2021, 165, 612-618, doi: 10.1016/j.renene.2020.11.083.

[10] R. J. Deokate, ES Materials \& Manufacturing, 2020, 11, 16 19, doi: 10.30919/esmm5f938.

[11] G. Huang, Q. Geng, B. Xing, Y. Liu, Y. Li, Q. Liu, J. Jia, L. Chen, C. Zhang, Journal of Power Sources, 2020, 449, 227506 , doi: 10.1016/j.jpowsour.2019.227506.
[12] Y. Ma, M. Ma, X. Yin, Q. Shao, N. Lu, Y. Feng, Y. Lu, E. K. Wujcik, X. Mai, C. Wang, Z. Guo, Polymer, 2018, 156, 128-135, doi: 10.1016/j.polymer.2018.09.051.

[13] Y. Tian, X. Yang, A. Nautiyal, Y. Zheng, Q. Guo, J. Luo, X. Zhang, Advanced Composites and Hybrid Materials, 2019, 2, 151-161, doi: 10.1007/s42114-019-0075-4.

[14] S. S. Patil, T. S. Bhat, A. M. Teli, S. A. Beknalkar, S. B. Dhavale, M. M. Faras, M. M. Karanjkar, P. S. Patil, Engineered Science, 2020, 12, 38-51, doi: 10.30919/es8d1140.

[15] Y. Ma, C. Hou, H. Zhang, Q. Zhang, H. Liu, S. Wu, Z. Guo, Electrochimica Acta, 2019, 315, 114-123, doi: 10.1016/j.electacta.2019.05.073.

[16] Z. Zhuang, W. Wang, Y. Wei, T. Li, M. Ma, Y. Ma, Advanced Composites and Hybrid Materials, 2021, 4, 938-945, doi: 10.1007/s42114-021-00225-0.

[17] Y. Wei, W. Luo, X. Li, Z. Lin, C. Hou, M. Ma, J. Ding, T. Li, Y. Ma, Electrochimica Acta, 2022, 406, 139874, doi: 10.1016/j.electacta.2022.139874.

[18] Q. Wang, Y. Ma, X. Liang, D. Zhang, M. Miao, Chemical Engineering Journal, 2019, 371, 145-153, doi: 10.1016/j.cej.2019.04.021.

[19] F. Zhao, Y. Guo, X. Zhou, W. Shi, G. Yu, Nature Reviews Materials, 2020, 5, 388-401, doi: 10.1038/s41578-020-0182-4.

[20] H. F. Wang, L. Chen, H. Pang, S. Kaskel, Q. Xu, Chemical Society Reviews, 2020, 49, 1414-1448, doi: 10.1039/c9cs00906j. [21] Z. Caia, P. Wanga, J. Yanga, X. J. E. E. Wanga, ES Energy \& Environment, 2019, 5, 22-36, doi: 10.30919/esee8c320.

[22] P. Vairale, V. Sharma, B. Bade, A. Waghmare, P. Shinde, A. Punde, V. Doiphode, R. Aher, P. Subhash, S. Nair, Engineered Science, 2020, 11, 76-84.

[23] Y. Ma, C. Hou, H. Zhang, M. Qiao, Y. Chen, H. Zhang, Q. Zhang, Z. Guo, Journal of Materials Chemistry A, 2017, 5, 14041-14052, doi: 10.1039/c7ta03279j.

[24] W. Luo, Y. Wei, Z. Zhuang, Z. Lin, X. Li, C. Hou, T. Li, Y. Ma, Electrochimica Acta, 2022, 406, 139871, doi: 10.1016/j.electacta.2022.139871.

[25] Y. Wei, W. Luo, Z. Zhuang, B. Dai, J. Ding, T. Li, M. Ma, X. Yin, Y. Ma, Advanced Composites and Hybrid Materials, 2021, 4, 1082-1091, doi: 10.1007/s42114-021-00323-z.

[26] L. Yang, L. Huang, Y. Yao, L. Jiao, Applied Catalysis B: Environmental, 2021, 282, 119584, doi: 10.1016/j.apcatb.2020.119584.

[27] Y. Zhang, H. Guo, X. Li, J. Du, W. Ren, R. Song, Chemical Engineering Journal, 2021, 404, 26483, doi : 10.1016/j.cej.2020.126483.

[28] N. C. S. Selvam, J. Lee, G. H. Choi, M. J. Oh, S. Xu, B. Lim, P. J. Yoo, Journal of Materials Chemistry A, 2019, 7, $27383-$ 27393, doi: 10.1039/c9ta10664b.

[29] J. D. Desai, P. K. Baviskar, K. N. Hui, H. M. Pathan, ES Energy \& Environment, 2018, 2, 21-30, doi: 10.30919/esee8c208.

[30] N. Singh, S. Jana, G. P. Singh, R. K. Dey, Advanced Composites and Hybrid Materials, 2020, 3, 127-140, doi: 10.1007/s42114-020-00140-w. 
[31] Y. Wei, M. Zheng, W. Luo, B. Dai, J. Ren, M. Ma, T. Li, Y. Ma, Journal of Energy Storage, 2022, 45, 103715, doi: 10.1016/j.est.2021.103715.

[32] M. Zheng, Y. Wei, J. Ren, B. Dai, W. luo, M. Ma, T. Li, Y. Ma, Separation and Purification Technology, 2021, 277, 119455, doi: 10.1016/j.seppur.2021.119455.

[33] L. He, S. Huang, Y. Liu, M. Wang, B. Cui, S. Wu, J. Liu, Z. Zhang, M. Du, Journal of Colloid and Interface Science, 2021, 586, 538-550, doi: 10.1016/j.jcis.2020.10.119.

[34] Q. Jin, B. Ren, H. Cui, C. Wang, Applied Catalysis B: Environmental, 2021, 283, 119643, doi: 10.1016/j.apcatb.2020.119643.

[35] Y. Deng, H. Liu, X. Wei, L. Ding, F. Jiang, X. Cao, Q. Zhou, M. Xiang, J. Bai, H. Gu, Journal of Colloid and Interface Science, 2021, 585, 800-807, doi: 10.1016/j.jcis.2020.10.060.

[36] K. Cui, J. Fan, S. Li, M. F. Khadidja, J. Wu, M. Wang, J. Lai, H. Jin, W. Luo, Z. Chao, Nanoscale Advances, 2020, 2, 478-488, doi: $10.1039 / \mathrm{c} 9$ na00633h.

[37] W. Zhong, Z. Wang, N. Gao, L. Huang, Z. Lin, Y. Liu, F. Meng, J. Deng, S. Jin, Q. Zhang, L. Gu, Angewandte Chemie International Edition, 2020, 59, 22743-22748, doi: 10.1002/anie.202011378.

[38] Q. Hu, M. Tang, M. He, N. Jiang, C. Xu, D. Lin, Q. Zheng, Journal of Power Sources, 2020, 446, 227335, doi: 10.1016/j.jpowsour.2019.227335.

[39] S. Wang, Z. Xiao, S. Zhai, H. Wang, W. Cai, L. Qin, J. Huang, D. Zhao, Z. Li, Q. An, Journal of Materials Chemistry A, 2019, 7, 17345-17356, doi: 10.1039/c9ta05145g.

[40] X. X. Liu, R. Wu, Y. Wang, S. H. Xiao, Q. He, X. B. Niu, D. J. Blackwood, J. S. Chen, Electrochimica Acta, 2019, 311, 221229, doi: 10.1016/j.electacta.2019.03.212.

[41] Z. Shi, L. Yue, X. Wang, X. Lei, T. Sun, Q. Li, H. Guo, W. Yang, Journal of Alloys and Compounds, 2019, 791, 665-673, doi: 10.1016/j.jallcom.2019.03.259.

[42] D. Kim, P. Karthick Kannan, S. Mateti, C. H. Chung, ACS Applied Energy Materials, 2018, 1, 6945-6952, doi: 10.1021/acsaem.8b01310.

[43] P. Zhou, Y. Wu, C. Wang, H. Huang, D. Xing, Y. Liu, Z. Wang, P. Wang, Z. Zheng, H. Cheng, Y. Dai, B. Huang, Chemical Engineering Journal, 2021, 403, 126285, doi: 10.1016/j.cej.2020.126285.

[44] L. Li, C. Sun, B. Shang, Q. Li, J. Lei, N. Li, F. Pan, Journal of Materials Chemistry A, 2019, 7, 18003-18011, doi: 10.1039/c9ta05578a.

[45] C. Z. Yuan, Z. T. Sun, Y. F. Jiang, Z. K. Yang, N. Jiang, Z. W. Zhao, U. Y. Qazi, W. H. Zhang, A. W. Xu, Small, 2017, 13, 1604161, doi: 10.1002/smll.201604161.

[46] J. Li, X. Zhang, Z. Zhang, Z. Li, M. Gao, H. Wei, H. Chu, Electrochimica Acta, 2019, 304, 487-494, doi: 10.1016/j.electacta.2019.03.023.

[47] C. Du, Y. Men, X. Hei, J. Yu, G. Cheng, W. Luo, ChemElectroChem, 2018, 5, 2564-2570, doi: 10.1002/celc. 201800630 .

[48] J. Li, Z. Yang, Y. Lin, J. Wang, F. Jiao, Y. Gong, New Journal of Chemistry, 2020, 44, 8578-8586, doi: 10.1039/d0nj00534g.
[49] F. Du, Z. Chen, Y. Zhang, H. He, Y. Zhou, T. Li, Z. Zou, Electrochemistry Communications, 2019, 99, 22-26, doi: 10.1016/j.elecom.2018.12.009.

[50] Z. Cui, Y. Ge, H. Chu, R. Baines, P. Dong, J. Tang, Y. Yang, P. M. Ajayan, M. Ye, J. Shen, Journal of Materials Chemistry A, 2017, 5, 1595-1602, doi: 10.1039/c6ta09853c.

[51] G. Chen, X. Chen, K. Song, N. Zhao, W. Wang, G. Yin, Y. Liu, ChemistrySelect, 2019, 4, 12328-12332, doi: 10.1002/slct.201902553.

[52] Y. Cheng, M. Zhai, M. Guo, Y. Yu, J. Hu, Applied Surface Science, 2019, 467-468, 1113-1121, doi: 10.1016/j.apsusc.2018.10.230.

[53] E. Kamali-Heidari, Z. L. Xu, M. H. Sohi, A. Ataie, J. K. Kim, Electrochimica Acta, 2018, 271, 507-518, doi: 10.1016/j.electacta.2018.03.183.

[54] J. Li, M. Yan, X. Zhou, Z. Q. Huang, Z. Xia, C. R. Chang, Y. Ma, Y. Qu, Advanced Functional Materials, 2016, 26, 6785-6796, doi: 10.1002/adfm.201670165.

[55] L. Zeng, K. Sun, X. Wang, Y. Liu, Y. Pan, Z. Liu, D. Cao, Y. Song, S. Liu, C. Liu, Nano Energy, 2018, 51, 26-36, doi: 10.1016/j.nanoen.2018.06.048.

Publisher's Note: Engineered Science Publisher remains neutral with regard to jurisdictional claims in published maps and institutional affiliations. 